\title{
The perceived feasibility and acceptability of a conceptually challenging exercise training program in older adults
}

\author{
Clint T Miller' \\ Megan Teychenne ${ }^{2}$ \\ Jaimie-Lee Maple ${ }^{2}$ \\ 'School of Exercise and Nutrition \\ Sciences, Deakin University, Geelong, \\ VIC, Australia; ${ }^{2}$ Institute for Physical \\ Activity and Nutrition (IPAN), School \\ of Exercise and Nutrition Sciences, \\ Deakin University, Geelong, VIC, \\ Australia
}

This article was published in the following Dove Press journal: Clinical Interventions in Aging

\begin{abstract}
Background: Exercise training is an essential component of falls prevention strategies, but they do not fully address components of physical function that leads to falls. The training approaches to achieve this may not be perceived as appropriate or even feasible in older adults. This study aims to assess the perceived feasibility and acceptability of novel exercise training approaches not usually prescribed to older adults.
\end{abstract}

Patients and methods: Fourteen adults were exposed to conceptually and physically demanding exercises. Interviews were then conducted to determine perceptions and acceptability of individual exercise tasks. Qualitative thematic analysis was used to identify themes. Results: Safety and confidence, acceptability, and population participation were the key themes identified. Staff knowledge, presence, program design, and overt safety equipment were important for alleviating initial apprehension. Although physically demanding, participants expressed satisfaction when challenged. Prior disposition, understanding the value, and the appeal of novel exercises were perceived to influence program engagement.

Conclusion: Given the evidence for acceptability, this type of training is feasible and may be appropriate as part of an exercise training program for older adults. Further research should be conducted to confirm that the physical adaptations to exercise training approaches as presented in this study occur in a similar manner to that observed in younger adults, and to also determine whether these adaptations lead to prolonged independence and reduced falls in older adults compared to usual care.

Keywords: falls, balance, qualitative analysis, thematic analysis, exercise/physical activity, power training, over-speed training

\section{Introduction}

Falls are a major cause of morbidity and mortality in older adults. Approximately $30 \%$ of older adults living independently and half of those living in aged care facilities suffer from at least one fall each year. ${ }^{1-3}$ Unfortunately, half of the falls suffered by older adults result in injury and $13 \%$ result in a fracture. ${ }^{1}$ Research shows that nearly two-thirds of falls occur during ambulation, stationary standing, or forward bending and up to $17 \%$ of older adults fall during tasks that require turning, changing direction, or lateral bending and reaching. ${ }^{4}$ Factors such as reduced gait efficiency due to small increases in gait variability, prolonged double-support phase, reduced gait speed, and increased step time variability are associated with the risk of multiple falls., ${ }^{5,6}$

Walking speed is a good predictor of health care utilization, nursing home admission, and mortality $;^{7}$ however, gait efficiency is a better predictor of physical function during aging. ${ }^{8}$ Decline in physical functions during the natural aging process occurs 
in part by reduction in neuromuscular function, poorer concentric contraction strength, antagonist muscle "stiffness",, 10 reduced type II muscle fibers, ${ }^{11}$ and impaired proprioception and cutaneous somatosensory system response. ${ }^{10}$ As a consequence, reactivity to loss of balance may be hampered by the inability to move the lower limb at speed. Muscular power is an important aspect of many activities of daily living. ${ }^{12}$ Reduced muscle power is associated with reduced lower limb functional performance ${ }^{13}$ and increased disability ${ }^{14}$ in older adults. Although muscular strength is a component of power (power $=$ force $\times$ velocity), the aging process results in greater decrease in power than strength ${ }^{15}$ and may be a better predictor of future falls. ${ }^{16}$ Additionally, reduced muscular efficiency, increased muscular co-activation, and higher body weight lead to a higher energy cost of walking, ${ }^{17-19}$ further contributing to a decline in physical capacity.

Current evidence demonstrates that exercise training consisting of strength training to fatigue and at least $60 \%$ of one repetition maximum, with challenging balance tasks is the most effective method for reducing the rates and risk of falls. ${ }^{20-22}$ However, there are potential benefits of high-velocity resistance and overspeed walking training for improving the muscular power and gait efficiency, but they do not currently form part of standard clinical practice. ${ }^{23}$ The use of heavy load, high-velocity resistance training is safe, ${ }^{24,25}$ improves physical function, ${ }^{26}$ and improves both power and strength to a greater extent than light load, high-velocity resistance training. ${ }^{12}$ Additionally, older adults who engage in running have a similar energy cost of walking when compared to younger adults and superior walking economy when compared to older adults who regularly walk. ${ }^{27}$ But running poses increased risk to the untrained, and may not be necessary to improve walking economy. Overspeed training on a treadmill with partial weight bearing in 75-85-year-old individuals appears to be safe and improves gait efficiency. ${ }^{28}$ However, in older adults with a falls history, partial weight bearing during overspeed treadmill walking has been shown to negatively affect gait variability, ${ }^{29}$ a key predictor of falls risk. ${ }^{30}$ Nonetheless, this type of exercise training approach may facilitate greater gains in physical performance and reduced risk of falls and loss of independence. These training interventions are yet to be studied in older adults at various risks of falls. This may be due to the physically and conceptually challenging nature of the exercises. There is no evidence to show that an exercise training program containing these types of exercises would be feasible in this population group. Previous research investigating older adults perceived barriers and facilitators to exercise training are well established ${ }^{31-33}$ and highlighted the fear of falling, fear of injury, fear of safety, and lack of perceived physical capacity as barriers to exercise training. However, these studies refer to physical activities with which most adults are familiar. Exercise training is necessary to improve reaction time, muscular power, and gait efficiency require training approaches that are normally reserved for athletes. No studies examine older adults' perceptions of participating in such physically challenging exercise programs. Therefore, the purpose of this study was to investigate the perceived feasibility and acceptability of physically and conceptually challenging exercises designed to improve physical performance, retain independence, and reduce fall risks among older adults.

\section{Patients and methods \\ Study design}

This stand-alone, single-exposure, qualitative study involved one-on-one semi-structured interviews with a convenience sample of older adults attending local medical and health clinics between December 2015 and March 2016. Human research ethics approval was obtained through Deakin University human research ethics committee in November 2015 (HEAG-H 161_2015).

\section{Participants}

Adults aged 60 years and older and living in the urban city area surrounding Melbourne, Australia were eligible to participate in this study.

\section{Exclusion criteria}

The study exclusion criteria were as follows: currently residing in a complex residential aged care facility; serious unstable cardiovascular condition such as acute myocardial infarction; congestive heart failure (New York Heart Association III); uncontrolled hypertension; serious musculoskeletal or neurologic condition such as previous vertebral crush fracture; history of osteoporotic fracture; Parkinson's disease; Huntington's disease; acute stroke; paresis of the lower limbs; uncontrolled diabetes mellitus; and severe cognitive impairment (inability to follow simple training instructions).

\section{Recruitment}

Posters were placed in selected medical and health centers. Snowball sampling, whereby participants were asked to share the study details with family and friends, was used to expedite recruitment. After a telephone screening $(n=19)$, where medical details were obtained, simple signs of cognitive function were evaluated (including memory, ability to follow conversation flow, and capacity to follow instructions 
regarding the second phase of screening [ie, making a general practitioner $\{\mathrm{GP}\}$ appointment and medical screening]). Eligible volunteers $(n=16)$ were required to obtain medical clearance from their treating GP prior to being recruited into the study. All participants received participant information in written and subsequent verbal explanation of the study details. Volunteers who met the inclusion criteria, gained medical clearance, and understood and signed the participant information and consent form were recruited into the study. Participants would then participate in the program and the interview, and after no new themes emerged from the interviews (data saturation), recruitment ended. ${ }^{34}$ A total of 14 participants were included in the final sample. Ethics approval was obtained from the Deakin University Human Research Ethics Committee (HEAG-H-161_2015).

\section{Program}

\section{Exercise training and testing}

Participants were exposed to a series of closely supervised exercise training tasks on a single visit, which was followed by a one-on-one, face-to-face semi-structured interview. Participants completed the exercise training session independently with the researcher who was also an Accredited Exercise Physiologist. On some occasions, participants were able to observe other participants completing the same exercises. There was no attempt made to prevent these observations.

\section{Overspeed treadmill walking}

A test of overground gait efficiency was first performed to calculate comfortable and maximal walking speed over $10 \mathrm{~m}$, which was repeated twice for each of the participants. The overspeed treadmill walking consisted of interval-based walking at 5\% above their $10 \mathrm{~m}$ maximum walking speed (work) for 10, 20, and $30 \mathrm{~s}$, interspersed by a slower walk (recovery) at $50 \%$ of their maximum walking speed for $60 \mathrm{~s}$. Participants attempted each work bout four times each before progressing onto the longer work bouts. All participants were fitted with a ceiling-mounted harness irrespective of their experience or confidence in using a treadmill.

\section{High-velocity resistance training}

Three repetition maximum (3RM) strength tests were performed to determine the heaviest weight that could be lifted three times, but no more than three times, for seated leg press and seated row. Both light (30\% of 3RM) and heavy load ( $80 \%$ of $3 \mathrm{RM})$ high-velocity resistance exercise for leg press and seated row was then performed following at least 20 minutes rest. A total of eight repetitions at each intensity were completed with a $10-15$ s rest between the repetitions. The tempo of $<1 \mathrm{~s}$ concentric (lifting) and $3 \mathrm{~s}$ eccentric (lowering) was encouraged.

\section{Dynamic balance task with external perturbations}

The dynamic balance task involved walking along a $30 \mathrm{~m}$ corridor wearing a single-point harness around the waist. Two researchers walked beside the participant holding onto the harness and provided a graded external perturbation. The same task was then applied while the participant walked heel to toe along a line $30 \mathrm{~m}$ long. Each task was completed twice.

\section{Agility course}

Participants were required to follow a verbally guided agility course competing against time after first walking slowly through the course with a researcher. The agility course involved walking forward, side stepping in each direction, walking backward, bending down to touch a bench set at mid tibia height, and nine changes in direction. The course was completed twice, and the goal for the second attempt was to beat the time of the first attempt.

\section{Partner resisted walking}

Participants wore a non-elastic resisted walking band and waist harness. They were required to walk along a $30 \mathrm{~m}$ corridor while resistance was applied to the band to slow the walking speed. Four $30 \mathrm{~m}$ walking bouts were completed with a supporting researcher walking alongside the participant.

\section{Measures}

Measures of physical function and balance were obtained prior to participation in the exercise training tasks to guide prescription of individualized exercise variables and were used to highlight the functional characteristics of the population group studied. These measures included weight, height, and body mass index, 6-minute walk, ${ }^{35}$ 3RM leg press, ${ }^{36}$ Berg balance scale, ${ }^{37}$ timed up and go, ${ }^{38} 30 \mathrm{~s}$ sit to stand, ${ }^{39}$ $10 \mathrm{~m}$ maximal walking speed, ${ }^{40}$ and hand grip strength. ${ }^{41}$

\section{Perceived feasibility of exercise program}

Following the single-session exercise program exposure, participants were interviewed (one-on-one, face-to-face with the researcher who was not involved with exercise delivery) to answer the following research question: what is the perceived feasibility and acceptability of physically and conceptually challenging exercises designed to improve 
physical performance, retain independence, and reduce fall risks among older adults?

A semi-structured interview schedule was developed by two researchers (CM and MT) in order to obtain answers for key research questions. Participants were asked about their current exercise routine as well as the factors that may influence their decision to engage in physical activity and/or exercise programs (eg, qualification of person leading the program, expected outcomes, and social engagement). Participants' perceptions of the program prior to trialing the exercises were assessed through questions such as "Thinking back to before you came along today, how were you feeling about the session?," "Was there anything that worried you about the exercises before you attempted them?," and

Based on what you knew about the program before trialing the exercises, do you feel that the exercises would be appropriate for someone like you and others in your age group?

Participants were also asked about how comfortable or confident they were feeling prior to the session in regards to each specific exercise in the program (in which photos of them completing each exercise were used as prompts). Following this, participants' perceptions of the exercise program having completed it were assessed through questions such as "Thinking about how you feel now that you have completed today's session, what kinds of things are you now feeling about the session?," "How different/similar are these exercises to exercises you have attempted in the past/exercises you currently do?," "What did you like (and dislike) about today's session? Why?," and "Were you surprised at how well you did at some of the exercises? Which ones? Why?" Participants were also asked about whether undertaking the session had changed their perceptions of undertaking each specific exercise in the program. Interviews were 25-35 minutes in length.

\section{Statistical analysis}

Descriptive statistics on demographic data were analyzed using SPSS software (version 21). Interviews were audio recorded and later transcribed. During these interviews, the interviewer/researcher (MT) made detailed notes on key points, with suggested codes and key themes summarized at the conclusion of all interviews. This information was later utilized as one method of researcher triangulation. To further ensure reliability of coding and themes, a second method of researcher triangulation was employed where two researchers independently coded a subsample of transcripts $(n=4) .{ }^{42}$
Researchers then met to discuss and resolve any discrepancies in coding (note: no major discrepancies were observed). For final qualitative analysis, NVivo software was used to organize data from which a thematic analyses was performed, following the methods described by Braun and Clark. ${ }^{43}$ Thematic analysis was chosen as it allows for flexibility and has been identified as an accessible tool for providing rich and detailed qualitative data. ${ }^{43,44}$ First, interview transcripts were repeatedly read by the researcher (JM; Phase I) and then data were coded into subcategories (eg, equipment) within NVivo (Phase II). Following this, major categories were created by grouping similar codes/subcategories together (eg, program design features; Phase III). Candidate (ie, preliminary) themes were identified and reviewed through linking common ideas (categories/subthemes; Phase IV) and once the thematic map was satisfactory, key themes were defined and named (Phase V; eg, safety and confidence, acceptability, and population participation themes). During Phase VI (analysis and write-up), themes were linked to direct quotes and presented with participant's sex and age. Consistent with Braun and Clarke's ${ }^{43,45}$ view that prevalence does not necessarily indicate the importance of the theme, inclusion was based on the extent to which the theme helped expand on knowledge to answer the research question, rather than simply occurring within the data.

\section{Results}

Table 1 represents the demographic and functional characteristics of the sample $(\mathrm{N}=14)$.

\section{Overview}

As illustrated in Figure 1, three key themes, including six subthemes, were identified. Generally, participants expressed

Table I Participants' demographic and functional characteristics

\begin{tabular}{ll}
\hline Characteristics & Mean (SEM) \\
\hline Age, years & $71 . \mathrm{I}(8.3)^{\mathrm{a}}$ \\
$\mathrm{Sex}, \mathrm{M}(\%)$ & $8(57)$ \\
$\mathrm{BMI}, \mathrm{kg} / \mathrm{m}^{2}$ & $27.3(1.5)$ \\
Waist circumference, cm & $99.6(3.8)$ \\
6MWT distance, $\mathrm{m}$ & $456.9(45.0)$ \\
Timed up and go, sec & $8.2(\mathrm{I} .2)$ \\
$30 \mathrm{~s}$ sit to stand, reps & $16.3(2.2)$ \\
Comfortable over-ground walking speed, $\mathrm{m} / \mathrm{sec}$ & $1.24(0.08)$ \\
Maximal over-ground walking speed, $\mathrm{m} / \mathrm{sec}$ & $1.79(0.15)$ \\
Dominant handgrip strength, kg & $26.9(2.5)$ \\
Berg balance scale, total score & $50.2(3.0)$ \\
\hline
\end{tabular}

Note: aStandard deviation.

Abbreviations: BMI, body mass index; M, male; reps, repetitions; SEM, standard error of the mean; $6 \mathrm{MWT}$, six-minute walk test. 


\section{Theme 1: safety and confidence}

1.1 Staff

- Treatment of staff

- Qualifications

- Physical presence
1.2 Program design features

- Equipment

- Individual tailoring

- Familiarity

- Modeling

\section{Theme 2: acceptability}

2.1 Prior disposition

- Appeal of trying something new

- Enjoyment
2.2 Outcomes

- Discovering ability level

- Preference for conceptually challenging exercises

\section{Theme 3: population participation}

3.1 Barriers

- Cost

- Location

- Time
3.2 Facilitators

- GP referral

- Word of mouth
Figure I Themes identified from interviews with older adults on the feasibility and acceptability of a conceptually challenging exercise training program.

Abbreviation: GP, general practitioner.

their enjoyment in partaking in the novel exercise training program. An initial apprehension in regards to a few of the exercises (namely, the overspeed treadmill exercise and high-velocity resistance training) was discussed by a few participants, although staff and program design features were identified in regard to alleviating this uneasiness and ultimately making the participants feel safe. Prior dispositions and pleasing outcomes were discussed with regards to the acceptability and enjoyment of the program. In addition, participants also identified factors that they believed would facilitate others in their age group to participate in similar population programs as well as possible barriers.

\section{Safety and confidence themes}

Safety themes refer to the staff and program design features identified by participants as facilitating feelings of comfort and, therefore, increasing their confidence to challenge themselves within the exercise training program.

\section{Staff}

The staff administering the program was a major subtheme identified by participants as influencing their comfort within the program.

\section{Treatment from staff}

Appreciation of the treatment that the participants received from staff administering the program was frequently expressed in regards to the program. Congratulating the achievements and encouraging individuals to push themselves in a respectful manner were all discussed as beneficial to increasing comfort in participating in the program.

Their concern for their participants, their enthusiasm ... you were congratulated and I felt that was very important.

[Female, 76]

\section{Qualifications}

Qualifications of the staff members administering the program influenced feelings of safety. Participants expressed that the knowledge that the staff members were adequately trained and educated in the area led to the belief that they were unlikely to be placed in a situation of risk. This, therefore, reduced apprehension when approaching a conceptually challenging exercise.

Qualifications are important because you want to know that what they're laying out for you is going to be beneficial and not going to cause harm. [Male, 63]

\section{Physical presence}

The presence of staff was discussed as a facilitator for participants to attempt exercises and challenge themselves in a way they would not normally feel comfortable.

Knowing that there were people there, that if something went wrong you know ... was someone there that would actually know what to do. [Female, 65]

\section{Program design features}

Participants discussed multiple design features of the program which influenced feelings of safety.

\section{Equipment}

The majority of participants expressed that they felt comfortable to challenge themselves without the fear of falling and achieve higher goals due to the safety equipment in place. The harness used within the overspeed walking task was frequently discussed in this respect.

They harnessed me up and I felt 100\% secure. [Female, 66] I could not have reached that speed without a harness.

[Male, 68] 


\section{Individual tailoring}

The individual tailoring of the program created a sense of ease for the participants. Participants expressed that each exercise was structured based on their individual ability, which helped them to feel as though goals were within their limits.

They've given us a program to work on, tailor made to our requirements and limitations. [Male, 82]

\section{Familiarity}

Familiarity was discussed by most of the participants as a factor that reduced apprehension toward conceptually challenging exercises within the program. Repetition of exercises was identified as a way to alleviate initial anxiety by slowly becoming familiar with the task's requirements and gradually increasing confidence.

It's like anything else [...] you've only got to do it a couple of times until you get used to it, you think, "oh this is great" and then you can do it a bit more. [Male, 82]

Comfort through familiarity was also discussed by a few participants in regards to exercises being similar to previous experiences, however, perhaps with an extra element.

I'd done a similar one with the falls prevention program, not quite so much weight as I was doing in that last bit but not a problem. [Female, 76]

\section{Modeling}

Individuals who completed the program with other participants in the room expressed that watching someone completes the activity prior to their own attempt helped to increase their confidence.

I was able to watch other people doing it so, yes, I think I can do that. [Female, 65]

\section{Acceptability themes}

Prior dispositions and outcomes were both subthemes discussed in regards to acceptance of the exercise training program.

\section{Prior disposition}

Prior dispositions refer to thoughts and feelings toward the program prior to participation, which impacted acceptance of the program.

\section{Appeal of trying something new}

Attempting a training program with exercises individuals had never experienced was seen by some as an appealing reason for participation. Multiple participants expressed being excited about trying something that would get them out of their normal routine or "comfort zone".

I was a bit excited that it was something new, and I'm always keen to try something new and different and I think that helps. [Male, 82]

\section{Outcomes}

Outcome subthemes refer to program effects that influenced participants' overall experience and acceptance.

\section{Discovering ability level}

Most participants expressed their surprise at what they could achieve, in regards to completing conceptually challenging exercises such as walking at higher speeds than usual, lifting heavier weights than expected, having strength in muscles not often used, and completing the program without feeling exhausted. Most participants felt challenged, but were pleasantly surprised by their ability after undertaking the exercises, in particular, that of the overspeed walking and high-velocity resistance training.

I surprised myself with how much I managed to achieve and that was great. [Female, 76]

These accomplishments were suggested by a few participants to be an influencing factor in the likeability of the program.

\section{Enjoyment}

The outcome of overall enjoyment in the exercise training program was a common subtheme expressed by most participants.

I really enjoy it, I thought it was great and I'm glad I did do it. [Female, 65]

A few participants furthered this by expressing that if they were not to enjoy an exercise program, they would be unlikely to attend regularly.

It has to keep being interesting. If it doesn't keep your interest it becomes boring, tedious and I'm not going to go today. [Female, 62]

\section{Preference for conceptually challenging exercises}

Numerous participants discussed that as a result of this program, they had developed a preference for the "new" (conceptually challenging) exercises experienced, rather than the more traditional (less-challenging) exercises they may have previously experienced. 
I would prefer to do some of these things on a regular basis

here and drop some of the other ones. [Male, 78]

In addition, a few discussed the desire to have these exercises incorporated into their normal falls prevention program.

I'd like to see, if possible, some of the more strenuous ones ... incorporated in the normal falls program. [Male, 78]

\section{Population participation themes}

Participants discussed what they believed would be the likelihood of people in their age group within the population of accepting and participating in a program similar to the one they experienced. Subthemes were categorized into barriers and facilitators to participating in such exercise programs.

\section{Barriers}

Barriers refer to factors that would make it difficult to encourage participation in the general population.

\section{Cost}

Cost was discussed in regards to a possible barrier to participation. Although some participants mentioned that they would happily pay for such a program, others did not agree. Individuals expressed the difficulty with people of their age group being on pensions, and therefore, the overall price range suggested was between $\$ 5$ and 20 per week. A few participants believed that such a program should be covered by health care funds.

\section{Location}

Location was also discussed as a possible barrier to participation. Although individuals enjoyed the program and could see the benefits, some mentioned that they would not be willing to travel too far.

I wouldn't want to travel too far for it. I would want it to be easily accessible. [Male, 63]

\section{Time}

Time was also discussed as a potential barrier. This was in regards to both lack of available free time and also the time of day that the program would be offered.

Fairly busy in retirement, so it would need to be the right length. [Male, 63]

$[\ldots]$ time too in the day. I prefer daytime now, getting older

I can't be bothered going out at night. [Female, 62]

\section{Facilitators}

Facilitators refer to factors that individuals believed would make participation from their age group more likely.

\section{GP referral}

GP referral was discussed by a couple participants who mentioned that they believed this approach would increase the probability of attendance to such a program.

It's probably the best way because a doctor could influence, they know the condition of the patient, therefore they can say, knowing the program, what's good for you, and what should be tackled. [Male, 82]

\section{Word of mouth}

Word of mouth advertisement was the most commonly agreed upon approach to most likely encourage attendance within their population group.

People see advertising but unless you know somebody that's - or somebody says "look I do this and it's really fantastic." I think that's more. [Female, 65]

\section{Discussion and implications}

The aim of this study was to determine the feasibility and acceptability of a physically demanding exercise training program consisting of high-velocity resistance training, overspeed treadmill walking, and demanding locomotor balance and agility training drills in older adults. With the exception of high-velocity resistance training, ${ }^{46-48}$ these training approaches have not been well researched in older adults. Reasons may include that older adults are not open to engaging in such provocative tasks in the community health environment, despite the potential benefits of maintaining physical function and independence, ${ }^{26,28}$ or reducing falls rates to a greater extent than traditional falls prevention programs..$^{20,21}$

\section{Acceptability of a physically demanding exercise training program}

In the current study, safety was reported as a factor that would influence participation in the program. An increase in the perception of safety was related to two closely related factors associated with the exercise professional (accredited exercise physiologist). Similar to previous research in healthy community-dwelling older adults (mean age 71-73 years), ${ }^{31,32}$ participants felt safer in the knowledge that the exercise professional was tertiary qualified with training in clinical populations. Additionally, we observed the importance of 
direct supervision of the participants. These findings align with a recent systematic review in which supervision was shown to increase adherence across a range of exercise programs in healthy older adults aged $>65$ years. ${ }^{49}$ Similarly, supervision was a key theme that emerged from a series of focus groups held among 52 older adults (mean age 71 years). ${ }^{31}$ These beliefs were further confirmed in this study, with participants reporting that they would not undertake such an exercise in a gym-based environment due to concerns of staff qualifications and training and lack of supervision. Overt safety precautions were another factor associated with the environment that were important considerations for participants of this study in their preparedness to attempt a conceptually challenging task that is perceived as high risk. Perceptions of safety were reported to influence adherence to exercise training in older adults (mean age 71 years) when undertaking exercise programs, ${ }^{31}$ with a recent systematic review highlighting that these perceptions may both positively and negatively influence adherence pending how these concerns are addressed on a personal level. ${ }^{50}$ Of note, most participants reported that seeing the roof-mounted harness, feeling comfortable in the harness, and "testing" the harness reduced the fear of falling and injury and increased perception of safety.

These findings suggest that the exercise professionals' understanding, support, and encouragement may lead to greater self-efficacy and increased motivation to attempt a new or more challenging, but familiar exercise task. Previous research examining exercise program in older adults (mean age $>65$ years) has reported similar results, with adherence and motivation increasing with greater levels of social support. ${ }^{31,49}$ Some participants in our trial reported that the increased confidence allowed them to walk at a faster speed than perceived possible. In addition to being initially surprised by their capacity (eg, during 3RM and maximum walking speed tests specifically), participants felt more confident with the exercise because of the transparency of determining exercise intensity based off their individual test outcomes (eg, proportion of 3RM, or gait speed), but also understanding the specific purpose of the exercises for preventing physical deconditioning and falls risk. Personal messages associated with both improving and maintaining health have been shown to act as motivators/facilitators in older adults (mean age 69-73 years) undertaking exercise programs. ${ }^{31,32}$ Furthermore, this "tailored" approach has been previously reported as an important component to engaging and challenging both older adults (mean age 71 years) ${ }^{31}$ and adults in general. ${ }^{50}$ It would, therefore, be important to clearly explain the relationship between test performance and exercise prescription with expected outcomes in an attempt to improve exercise program engagement and improve exercise self-efficacy. These findings highlight that the purpose of the exercise program and linking the specific exercise tasks with expected participant outcomes may facilitate acceptance of the program.

\section{Perceived feasibility of the program}

Interestingly, no novel barriers were shown to be associated with the exercise program in this study when compared to previous research examining various exercise programs within older adults (mean age 71 years), ${ }^{31}$ despite the uniquely challenging nature of the exercises trialed in this study. Similar to previous research, the most common barrier reported was related to the cost of attending such a program, geographic accessibility, and time limitations. ${ }^{31,32}$ Participants in this study believed that referral or advice from their treating GP would facilitate initial attendance. The notion of clinician involvement in referral to exercise programs has been shown to act as an enabler toward exercise programs in both healthy ${ }^{31,50,51}$ and clinical (eg, cancer patients) ${ }^{52}$ older populations and, therefore, should be considered when feasible from both a time and financial perspective. Another key factor commonly reported to facilitate exercise participation in older adults (mean age 69-73 years) is knowing friends or family that participate in the program or seeing peers complete similar programs. ${ }^{31,32}$ The observations from our study suggested that these concepts may reduce apprehension to engaging in a novel exercise program. This is likely due to the effect of modeling, which enhances exercise self-efficacy through observing someone else perceived as being similar to one's self complete a particular task and is consistent with existing social cognitive theory. ${ }^{53}$ The results from this study show that older adults enjoy being physically challenged, and in line with previous research, ${ }^{31,32}$ it appears that motivation for continued participation is more likely if the exercise is challenging, personally rewarding, and enjoyable. The novelty of the exercises in this study contributed to the likability despite the challenge of the tasks.

\section{Strengths and limitations}

A key strength of this study is the qualitative design which allowed for rich and in-depth insights that quantitative studies would not otherwise identify. Limitations of this study should, however, be acknowledged. Although semi-structured interviews were used which allowed the interviewer to further explore conversations that were topical, ${ }^{54}$ the way some questions were structured may have limited some participant 
responses. Further, qualitative interviews can be subjected to social desirable responses from participants. Similarly, there is the possibility of researcher bias when analyzing qualitative data. However, we employed two methods of researcher triangulation to minimize this possibility.

\section{Future directions}

The unique nature of the exercise training approaches presented in this study is hypothesized to improve physical capacity and reduce falls rates to a greater extent than current exercise training guidelines for older adults. This study shows that older adults are capable of and are comfortable with undertaking such challenging exercise in a clinical setting under direct supervision. Future studies should be conducted to confirm proof of concept that the training approaches reported in this study lead to the expected physiological outcomes experienced in younger adults. It is expected that these types of training strategies would be suitable for primary and secondary prevention of falls in older adults, and should therefore be confirmed in further research. The authors acknowledge that many of the exercise approaches presented in this study require safety equipment that are not currently widely accessible, and therefore, translation of this and future research to the broader community may initially be limited.

\section{Conclusion}

A physically and initially conceptually challenging exercise program consisting of high and light load high-velocity resistance training, overspeed walking on a motorized treadmill, and agility training drills was well accepted and, therefore, should be trialed in older adults to prolong independent living and reduce risk of falls.

Although older adults suggested that they enjoyed being physically challenged through exercise training, it is important that the exercise training program be directly supervised by suitably qualified exercise professionals (eg, accredited Exercise Physiologists in Australia) using overt safety equipment and precautions. Older adults were particularly interested in and motivated when they understood the purpose of specific exercises and the relationship between tests of physical capacity and exercise prescription; thus, the dissemination of this information may increase acceptability and adherence to exercise programs, especially when novel exercises are being prescribed. Given the evidence for acceptability and the findings of this study, further research should, therefore, determine whether these types of exercise training lead to greater physical performance outcomes, prolonged independence, and reduced falls in older adults when compared to usual care.

\section{Acknowledgment}

This study was funded by Deakin University. An abstract of this work has previously been published at the Victorian Allied Health Research Symposium 2017. Partial results from this study were presented as an electronic poster.

\section{Author contributions}

CTM and MT contributed to the study design. CTM, MT, and JLM contributed to data collection, data analysis, interpretation, and preparation of the manuscript. All authors contributed toward data analysis, drafting and revising the paper and agree to be accountable for all aspects of the work.

\section{Disclosure}

The authors report no conflicts of interest in this work.

\section{References}

1. Bergland A, Wyller TB. Risk factors for serious fall related injury in elderly women living at home. Inj Prev. 2004;10(5):308-313.

2. Rubenstein LZ. Falls in older people: epidemiology, risk factors and strategies for prevention. Age Ageing. 2006;35 (Suppl 2):ii37-ii41.

3. Tinetti ME. Preventing falls in elderly persons. $N$ Engl J Med. 2003; 348(1):42-49.

4. Stevens J, Mahoney J, Ehrenreich H. Circumstances and outcomes of falls among high risk community-dwelling older adults. Inj Epidemiol. 2014;1(1):5.

5. Callisaya ML, Blizzard L, Schmidt MD, et al. Gait, gait variability and the risk of multiple incident falls in older people: a population-based study. Age Ageing. 2011;40(4):481-487.

6. VanSwearingen JM, Studenski SA. Aging, motor skill, and the energy cost of walking: implications for the prevention and treatment of mobility decline in older persons. J Gerontol A Biol Sci Med Sci. 2014; 69(11):1429-1436.

7. Schrack JA, Simonsick EM, Ferrucci L. The energetic pathway to mobility loss: an emerging new framework for longitudinal studies on aging. J Am Geriatr Soc. 2010;58(Suppl 2):S329-S336.

8. Wert DM, Brach JS, Perera S, VanSwearingen J. The association between energy cost of walking and physical function in older adults. Arch Gerontol Geriatr. 2013;57(2):198-203.

9. Brown M, Fisher JS, Salsich G. Stiffness and muscle function with age and reduced muscle use. J Orthop Res. 1999;17(3):409-414.

10. Vandervoort AA. Aging of the human neuromuscular system. Muscle Nerve. 2002;25(1):17-25.

11. Martin JC, Farrar RP, Wagner BM, Spirduso WW. Maximal power across the lifespan. J Gerontol A Biol Sci Med Sci. 2000;55(6): M311-M316.

12. de Vos NJ, Singh NA, Ross DA, Stavrinos TM, Orr R, Fiatarone Singh MA. Optimal load for increasing muscle power during explosive resistance training in older adults. J Gerontol A Biol Sci Med Sci. 2005;60(5):638-647.

13. Md JFB, Kiely DK, Herman S, et al. The relationship between leg power and physical performance in mobility-limited older people. J Am Geriatr Soc. 2002;50(3):461-467.

14. Foldvari M, Clark M, Laviolette LC, et al. Association of muscle power with functional status in community-dwelling elderly women. J Gerontol A Biol Sci Med Sci. 2000;55(4):M192-M199. 
15. Izquierdo M, Ibanäez J, Gorostiaga E, et al. Maximal strength and power characteristics in isometric and dynamic actions of the upper and lower extremities in middle-aged and older men. Acta Physiol Scand. 1999; 167(1):57-68.

16. Skelton DA, Kennedy J, Rutherford OM. Explosive power and asymmetry in leg muscle function in frequent fallers and non-fallers aged over 65. Age Ageing. 2002;31(2):119-125.

17. Hortobagyi T, Finch A, Solnik S, Rider P, DeVita P. Association between muscle activation and metabolic cost of walking in young and old adults. J Gerontol A Biol Sci Med Sci. 2011;66(5):541-547.

18. Ortega JD, Farley CT. Effects of aging on mechanical efficiency and muscle activation during level and uphill walking. J Electromyogr Kinesiol. 2015;25(1):193-198.

19. Laroche DP, Marques NR, Shumila HN, Logan CR, Laurent RS, Goncalves M. Excess body weight and gait influence energy cost of walking in older adults. Med Sci Sports Exerc. 2015;47(5):1017-1025.

20. Gillespie LD, Robertson MC, Gillespie WJ, et al. Interventions for preventing falls in older people living in the community. Cochrane Database Syst Rev. 2012;9(11):CD007146.

21. Sherrington C, Tiedemann A, Fairhall N, Close JCT, Lord SR. Exercise to prevent falls in older adults: an updated meta-analysis and best practice recommendations. NS W Public Health Bull. 2011;22(4): 78-83.

22. Sherrington C, Michaleff ZA, Fairhall N, et al. Exercise to prevent falls in older adults: an updated systematic review and meta-analysis. Br J Sports Med. 2017;51(24):1750-1758.

23. Tiedemann A, Sherrington C, Close JC, Lord SR. Exercise and sports science australia position statement on exercise and falls prevention in older people. J Sci Med Sport. 2011;14(6):489-495.

24. Liu CJ, Latham NK. Progressive resistance strength training for improving physical function in older adults. Cochrane Database Syst Rev. 2009(3):Cd002759.

25. Raymond MJ, Bramley-Tzerefos RE, Jeffs KJ, Winter A, Holland AE. Systematic review of high-intensity progressive resistance strength training of the lower limb compared with other intensities of strength training in older adults. Arch Phys Med Rehabil. 2013;94(8):1458-1472.

26. Glenn JM, Gray M, Binns A. The effects of loaded and unloaded highvelocity resistance training on functional fitness among communitydwelling older adults. Age Ageing. 2015;44(6):926-931.

27. Ortega JD, Beck ON, Roby JM, Turney AL, Kram R. Running for exercise mitigates age-related deterioration of walking economy. PLoS One. 2014;9(11):e113471.

28. Thomas EE, De Vito G, Macaluso A. Speed training with body weight unloading improves walking energy cost and maximal speed in 75- to 85-year-old healthy women. J Appl Physiol. 2007;103(5):1598-1603.

29. Kyvelidou A, Kurz MJ, Ehlers JL, Stergiou N. Aging and partial body weight support affects gait variability. J Neuroeng Rehabil. 2008; $5: 22$.

30. Barak Y, Wagenaar RC, Holt KG. Gait characteristics of elderly people with a history of falls: a dynamic approach. Phys Ther. 2006; 86(11):1501-1510.

31. Bethancourt HJ, Rosenberg DE, Beatty T, Arterburn DE. Barriers to and facilitators of physical activity program use among older adults. Clin Med Res. 2014;12(1-2):10-20.

32. Biedenweg K, Meischke H, Bohl A, et al. Understanding older adults' motivators and barriers to participating in organized programs supporting exercise behaviors. J Prim Prev. 2014;35(1):1-11.

33. Newson RS, Kemps EB. Factors that promote and prevent exercise engagement in older adults. J Aging Health. 2007;19(3):470-481.

34. Guest G, Bunce A, Johnson L. How many interviews are enough? An experiment with data saturation and variability. Field Methods. 2006; 18(1):59-82.
35. Kervio G, Carre F, Ville NS. Reliability and intensity of the six-minute walk test in healthy elderly subjects. Med Sci Sports Exerc. 2003; 35(1):169-174

36. Shaw CE, McCully KK, Posner JD. Injuries during the one repetition maximum assessment in the elderly. J Cardiopulm Rehabil Prev. 1995; 15(4):283-287.

37. Berg KO, Wood-Dauphinee SL, Williams JI, Maki B. Measuring balance in the elderly: validation of an instrument. Can J Public Health. 1991;83:S7-S11.

38. Podsiadlo D, Richardson S. The timed "up \& go": a test of basic functional mobility for frail elderly persons. J Am Geriatr Soc. 1991;39(2): $142-148$.

39. Jones CJ, Rikli RE, Beam WC. A 30-s chair-stand test as a measure of lower body strength in community-residing older adults. Res $Q$ Exerc Sport. 1999;70(2):113-119.

40. Berryman N, Bherer L, Nadeau S, et al. Executive functions, physical fitness and mobility in well-functioning older adults. Exp Gerontol. 2013;48(12):1402-1409.

41. Abizanda P, Navarro JL, García-Tomás MI, López-Jiménez E, Martínez-Sánchez E, Paterna G. Validity and usefulness of hand-held dynamometry for measuring muscle strength in community-dwelling older persons. Arch Gerontol Geriatr. 2012;54(1):21-27.

42. Carter N, Bryant-Lukosius D, DiCenso A, Blythe J, Neville AJ. The use of triangulation in qualitative research. Paper presented at: Oncology Nursing Forum; 2014

43. Braun V, Clarke V. Using thematic analysis in psychology. Qual Res Psychol. 2006;3(2):77-101.

44. Green J, Willis K, Hughes E, et al. Generating best evidence from qualitative research: the role of data analysis. Aust NZJ Public Health. 2007;31(6):545-550.

45. Braun V, Clarke V. Successful Qualitative Research: A Practical Guide for Beginners. London: Sage; 2013.

46. Gianoudis J, Bailey C, Sanders K, et al. Osteo-cise: strong bones for life: protocol for a community-based randomised controlled trial of a multi-modal exercise and osteoporosis education program for older adults at risk of falls and fractures. BMC Musculoskelet Disord. 2012; 13(1):78.

47. Henwood TR, Taaffe DR. Improved physical performance in older adults undertaking a short-term programme of high-velocity resistance training. Gerontology. 2005;51(2):108-115.

48. Cadore EL, Casas-Herrero A, Zambom-Ferraresi F, et al. Multicomponent exercises including muscle power training enhance muscle mass, power output, and functional outcomes in institutionalized frail nonagenarians. Age (Dordr). 2014;36(2):773-785.

49. Picorelli AMA, Pereira LSM, Pereira DS, Felício D, Sherrington C. Adherence to exercise programs for older people is influenced by program characteristics and personal factors: a systematic review. J Physiother. 2014;60(3):151-156.

50. Morgan F, Battersby A, Weightman AL, et al. Adherence to exercise referral schemes by participants-what do providers and commissioners need to know? A systematic review of barriers and facilitators. $B M C$ Public Health. 2016;16(1):1-11.

51. Burton E, Farrier K, Lewin G, et al. Motivators and barriers for older people participating in resistance training: a systematic review. J Aging Phys Act. 2017;25(2):311-324.

52. Craike M, Gaskin CJ, Courneya KS, et al. Predictors of adherence to a 12-week exercise program among men treated for prostate cancer: engage study. Cancer Med. 2016;5(5):787-794.

53. Bandura A. Human agency in social cognitive theory. Am Psychol. 1989;44(9):1175

54. DiCicco-Bloom B, Crabtree BF. The qualitative research interview. Med Educ. 2006;40(4):314-321. 
Clinical Interventions in Aging

\section{Publish your work in this journal}

Clinical Interventions in Aging is an international, peer-reviewed journal focusing on evidence-based reports on the value or lack thereof of treatments intended to prevent or delay the onset of maladaptive correlates of aging in human beings. This journal is indexed on PubMed Central, MedLine,

CAS, Scopus and the Elsevier Bibliographic databases. The manuscript management system is completely online and includes a very quick and fair peer-review system, which is all easy to use. Visit http://www.dovepress. $\mathrm{com} /$ testimonials.php to read real quotes from published authors.

Submit your manuscript here: http://www.dovepress.com/clinical-interventions-in-aging-journal 